\title{
ADMINISTRAÇÃO POR EXCEÇÃO: CONSIDERAÇÕES E UMA PROPOSTA
}

\author{
Maria Auxiliadora de Medeiros Valle (Dorinha) ${ }^{1}$
}

\begin{abstract}
Resumo
A proposta "Administração por Exceção" advém de solicitações dos empregados desde 1996, quando o Serviço Federal de Processamento de Dados (Serpro), subsidiado pela sua área de Qualidade, realizou o curso "Flexibilidade para mudanças na Qualidade", ocasionando alterações de normas e processos administrativos que resultaram, dentre outros, em "Horário Flexível". Ela é reforçada com a criação da Ouvidoria Interna Serpro, em 2001: um dos assuntos relatados pelos empregados é a "Administração por Exceção". Os relatos, bem como as solicitações apresentadas, servem de subsídios para o aperfeiçoamento da máquina administrativa, contribuindo para a qualidade dos serviços e para a mudança na cultura da empresa.
\end{abstract}

Palavras-chave: Administração. Exceção.

\begin{abstract}
The "Administration by Exception" proposal comes from the requests of employees since 1996, when the Federal Data Processing Service (Serpro), subsidized by its Quality area, conducted the course "Flexibility for changes in Quality", leading to changes in standards and administrative processes that resulted, among other things, in "Flexible schedule". And it is reinforced with the creation of the Serpro Internal Ombudsman in 2001: one of the subjects reported by the employees is "Administration by Exception". The reports, as well as the requests presented, serve as subsidies for the improvement of the administrative machinery, contributing to the quality of services and to the change in the company culture.
\end{abstract}

Keywords: Administration. Exception.

\section{DOI:10.37814/2594-5068.2019v2.p207-215}

1 Analista do Serpro. Especialista em Processo de Ouvidoria/Ombudsman. 1a Ouvidora do Serpro (2001/2004). Instrutora do "Curso de Capacitação: a Ouvidoria/Ombudsman nas Organizações", da ABO/RJ. Coordenadora do GEQUAL - Grupo Executivo da Qualidade, Saúde e Meio Ambiente. Autora de diversos trabalhos/Projetos, destacam-se: "Ouvidoria Interna do Serpro"; Sistema de Ouvidoria Serpro em Software Público e "Ouvidoria Externa Serpro: considerações e uma proposta" (trabalho vencedor/premiado no Tema Gestão Empresarial do Congresso Serpro de Tecnologia e Gestão Aplicadas a Serviços Públicos - ConSerpro 2005) -, implementado como Ouvidoria-Geral em maio de 2014. (maria.auxiliadora-valle@serpro.gov.br) ou (dorinha.valle@gmail.com.) Tel. (21) 99505-2396 


\section{INTRODUÇÃO}

Em 1996, o Serpro, subsidiado pela sua área de Qualidade, alterou a norma que regia a frequência dos Empregados para adaptá-la ao novo momento da Empresa e do mundo: a busca da produtividade, da gestão por resultados e do elemento diferencial da qualidade como marca. Essa alteração na norma é o que se chama até hoje de "Horário Flexível", aplicado para "humanizar" o cartão de ponto tradicional/catraca.

Após a flexibilização (um avanço em 1996), a empresa continuou avançando no domínio tecnológico da microinformática e conseguiu disponibilizar micro $1 \times 1$ aos seus empregados, e todos passam a ter acesso direto a correio eletrônico. A empresa assim se modernizou e, a partir de 1999, adotou o Ponto por Exceção, que tem embutido o horário flexível sem a necessidade de bater o ponto.

O assunto Administração por Exceção veio à tona, novamente, com a criação da Ouvidoria Interna do Serpro, em julho de 2001, que estabeleceu um canal vivo de comunicação por meio do qual os empregados (corpo funcional e gerencial) podem se manifestar diante da Direção da Empresa, ou seja, ele é um elo direto entre a diretoria e os empregados.

A Ouvidoria Interna revelou-se um instrumento importante de participação dos empregados no levantamento de problemas e de apresentação de propostas de solução, propiciando um constante feedback à organização no sentido de atendimento às necessidades dos empregados. Observe-se que o empregado ao reclamar e sugerir revela sua confiança de que a organização tem vitalidade e pode ser mais eficiente e eficaz com a participação de todos.

A partir dos assuntos relatados pelos empregados e com o intuito de promover a correção de processos e práticas administrativas, a Ouvidoria Interna reuniu-se com a Diretoria e com as áreas e divisões da empresa para apresentar sugestões de solução para os problemas e tratar a relação empresa-empregado.

Uma das principais sugestões da Ouvidoria Interna, baseada em demanda de empregados, foi a Administração por Exceção, a saber:

a) Implantar na Empresa, como um todo, a Administração por Exceção, como uma norma advinda da Diretoria.

b) Como norma, haverá espaço para tratar os casos específicos.

c) Os casos específicos, em especial os abusos (estatisticamente, no máximo de $20 \%$ ) serão tratados pela chefia imediata.

Dos acionamentos que a Ouvidoria Interna recebe, a maioria contém informações/sugestões benéficas que a empresa tem implementado gradativamente. Foi o que ocorreu com a Adoção da Administração por Exceção em áreas onde tal prática não era, ainda, adotada. Ao ouvir o empregado nas suas solicitações, retornando soluções de forma ágil e desburocratizada, ela confere credibilidade à organização e propicia o fortalecimento de uma cultura de cidadania.

À medida que o poder de proposição da Ouvidoria Interna se materializa em iniciativas como a Administração por Exceção, ela se revela um "agente de mudanças": por meio de sua atuação, mo- 
dificam-se normas, simplificam-se rotinas e economizam-se recursos. Assim, é estabelecida uma fonte de racionalidade crucial nos tempos pós-modernos de intensa competitividade.

Vale ressaltar que o papel da Ouvidoria Interna mostra-se importante em estruturas grandes e complexas, onde há distância entre a alta direção e o empregado, dificultando a percepção pela Diretoria do que se passa com ele. Propicia, pois, à cúpula administrativa, maior visualização do empregado.

A aceitação da Administração por Exceção acompanha: o avanço da Tecnologia da Informação e Comunicação (TIC) e das relações de trabalho (por exemplo, o teletrabalho); o que é preconizado pela Gestão da Qualidade; e o surgimento dos canais de cidadania, com a respectiva liberdade de escolha.

O grande desafio da nova era é conciliar os recursos tecnológicos com as novas formas de trabalho, fomentando a inovação, criando conexões e até mesmo gerando negócios.

\section{ANÁLISE}

A avassaladora revolução tecnológica que estamos presenciando de duas décadas para cá está abrindo espaço para o aparecimento de novos modelos de trabalho e de profissões. A aceleração tecnológica em todos os níveis provoca aumento de complexidade e mudanças drásticas na sociedade e nas organizações, exigindo alinhamento de valores, requerendo agregar valor.

Nos novos modelos, ouvir os empregados nas suas demandas (reclamações, sugestões e elogios) e mediar soluções é uma forma de conferir credibilidade à organização e oportunizar o fortalecimento de uma cultura de cidadania onde todos ganham. Associar-se a esses modelos requer uma visão crítica da organização: captar as mudanças concomitantemente com o acompanhamento dos interesses de seu público - interno e externo -, onde na busca da excelência o erro é admitido.

A organização que se dispõe a ouvir os empregados pode contar com sua fidelidade e motivação, inspirando-os a produzirem bens e serviços o melhor possível em prol de seu crescimento e da manutenção de bons resultados. Deve-se atentar para o fato de os empregados serem os que melhor conhecem os detalhes das operações da organização.

Percebe-se que o profissional dentro do ambiente de trabalho não é um robô ou uma máquina como é visto muitas vezes, mas sim um ser humano movido a razões e emoções. Basta lembrar da caricatura que Charlie Chaplin fez do mundo industrial em Tempos modernos (1936), onde retrata a neurose de Carlitos em meio às máquinas, aos cartões de ponto e à produção em série.

Segundo o professor Mário César FERREIRA, do Instituto de Psicologia da Universidade de Brasília (UnB), doutor em ergonomia (EPHE, Paris), o relógio de ponto é fruto da Revolução Industrial, que se consolidou com enfoque taylorista de tempos e movimentos da denominada administração científica e que até hoje ocupa lugar de destaque como instrumento de gestão. $\mathrm{E}$ acrescenta que há uma série de estudos e pesquisas indicando que a origem de uma série de indicadores críticos nas organizações (doenças, acidentes, estresse, retrabalho, perda de quali- 
dade, panes e rotatividade) está no controle rígido de horário.

Cabe ressaltar que os indicadores críticos não podem ser negligenciados, pois refletem a insatisfação que vai tomando conta do ambiente das organizações e gera efeitos significativos:

- Baixa qualidade no trabalho

- Baixa produtividade

- Turn-over indesejável

- Retrabalho

- Boicotes

- Falta de comprometimento

- E outros.

Já estamos há dois séculos do surgimento do capitalismo industrial e ainda hoje se percebe que a sociedade moderna não se livrou da métrica da produção: cada produto representa $\mathrm{x}$ horas de trabalho. Os conceitos de ética, de moral, do bem e do mal estão diretamente relacionados à condição de o homem encaixar-se ou não como uma engrenagem, como um parafuso, na máquina produtiva.

O binômio "comando-controle" sobre as pessoas está morrendo. No dia a dia e para o progresso da organização é preciso colocar em pleno funcionamento o cérebro e a capacidade inteligente das pessoas, de forma a acrescentar e enriquecer os processos e procedimentos.

No decorrer dos tempos as organizações não podem esquecer o fator da satisfação humana: empregados satisfeitos desempenham suas funções com eficácia.

O novo padrão de competitividade globalizada vem demonstrando que o trabalho também requer alma e que a motivação advém de pessoas felizes. A satisfação no trabalho resulta da percepção de que o trabalho realiza valores importantes relacionados ao próprio trabalho. $E$ as fontes de felicidade são, além das tarefas, o local, as pessoas e os estilos gerenciais.

A postura empresarial não pode apenas ser objetiva e pragmática, enxergando só lucro e capital (valor imediato ao negócio). Requer agora uma visão subjetiva quanto aos efeitos exercidos pelo trabalho sobre as pessoas, a qual agrega valor indireto, mas também faz com que as empresas se perpetuem.

A organização moderna deve estar preocupada com as pessoas que dão vida a seu negócio e agir de forma ecológica, dando atenção aos seres vivos que são parte integrante dela e que fazem o negócio acontecer.

Nos dias de hoje, a principal unidade produtiva da era da tecnologia está na cabeça dos trabalhadores. A energia desprendida quando a imaginação e a aspiração das pessoas se juntam fornece as diretrizes de conduta para os negócios prosperarem. Então, a gestão estratégica de pessoas tem de criar condições que possibilitem às pessoas comuns em cada setor da organização apresentar um desempenho excepcional.

No atual momento, o mais importante não é a questão temporal (regular horário e estatística de horas trabalhadas); o mais importante é, repita-se, a busca da produtividade, da gestão por resultados e do elemento diferencial da qualidade como marca. 
O fato de um empregado cumprir um horário rígido não significa dizer que produza mais. Uma produção mais eficiente muitas vezes advém de se adequar o cartão de ponto, o que requer uma mudança de cultura organizacional revendo valores, crenças, ritos e mitos.

Ricardo SEMLER, no livro Virando a própria mesa, escrito em 1988, descreve de forma simples, no capítulo 10, "As doenças da empresa - como diagnosticá-las antes do estado de coma", páginas 187-188, a questão do horário:

Horário é outra dor de cabeça. Assiduidade, pontualidade e disciplina são grandes preocupações da empresa. Pois não deviam ser. Não há razão nenhuma para isso. É só fazermos de conta que a empresa só contrata adultos responsáveis. Esta questão do horário é um desvirtuamento de ótica que causa profundas irritações aos dois lados, desnecessariamente. Uma outra maneira de olhar a coisa é a seguinte:

1. As empresas contratam as pessoas para atingir um resultado. Se todas elas chegarem religiosamente às $8 \mathrm{~h} 00$ e saírem às $17 \mathrm{~h} 17$, mas o resultado não for alcançado, tem-se não mais uma empresa, mas sim um colégio interno. Diga claramente às pessoas qual o objetivo e deixe uma latitude para elas decidirem como e quando fazerem. Assim é possível que se chegue ao final do ano com o resultado, mas sem uma estatística exata de horas trabalhadas. Qual é preferível?

2. Implante o horário móvel. Especialmente num aglomerado urbano como São Paulo, é insensato esperar que as pessoas consigam cronometrar os sinais, os ônibus e o trânsito para chegarem na hora. Isto causa estresse aos funcionários e faz com que já comecem o dia irritados ou desgastados. Um grande argumento contra o horário móvel é que as pessoas dependem uma das outras e não conseguem trabalhar se todas não estiverem lá. Na verdade, isso é só planejamento inadequado, porque em algumas horas do dia todos estarão juntos.

Em busca da produtividade, os relógios de ponto ficaram pesados demais para as grandes empresas e foram sendo deixados para trás. A retirada das catracas, por diversas empresas, corrobora uma posição de se tornarem empresas modernas, adotando um sistema informatizado baseado na confiança entre empregados e chefes. É preciso atentar que a confiança é uma palavra-chave para a organização moderna, que tem um patamar de excelência primando pela confiabilidade, credibilidade, crédito aos empregados, onde se dá valor ao conforto das pessoas.

A Bayer, pioneira nesse tipo de sistema, economizou U\$ 100 mil dólares em um ano de experiência sem 52 relógios e 3.400 cartões de ponto (isto em 1992).

O sistema adotado pela Bayer chama-se Administração por Exceção, o qual:

a) Não dispensa o empregado da obrigação de cumprir a jornada de trabalho prevista no contrato.

b) Nesse sistema, são digitadas apenas as ocorrências das exceções: horas extras, faltas não justificadas e atrasos não compensados.

c) Não exclui qualquer tipo de registro de frequência, só o torna um controle mais eficaz, moderno, atual e de acordo com os preceitos preconizados pela Gestão da Qualidade Total (GQT). 
d) Todos os empregados que estejam enquadrados no controle de ponto terão o respectivo espelho de ponto.

e) Pode ser adotado por empresas públicas e privadas no que diz respeito a registro de ponto. f) Atende ao aspecto legal do art. 74 da Consolidação das Leis do Trabalho (CLT), conforme preconizado para os estabelecimentos com mais de 10 (dez) empregados.

g) É uma prática baseada na confiança entre empregados e chefes (adotada por empresas modernas).

É interessante observar que existe um entendimento de que "o ponto nos protege". Sobre o "ponto nos protege", cabe esclarecer:

a) De fato, foram os trabalhadores que pediram o ponto. Isto quando nas fábricas não se tinha garantia de férias, licença-maternidade, hora extra, hora de almoço etc.

b) Com a era da TIC, as relações de trabalho se alteram e até o cartão de ponto deve ser modernizado e adequado às novas relações de trabalho.

c) Daí o surgimento do ponto inteligente, que é a Administração por Exceção/Registro de Frequência por Exceção.

A aposentadoria do cartão de ponto traz alívio aos empregados enquanto surgem novas fórmulas de organização industrial, com descentralização de poder e flexibilidade nas relações entre chefe e empregado.

O alívio provocado pela retirada do cartão de ponto melhora as atitudes e os sentimentos dos empregados em relação ao trabalho. $O$ deleite no trabalho produz muito mais gente feliz em relação às suas vidas profissionais, pessoais, familiares e sociais. O resultado são pessoas com energia positiva, que não opõem resistência, com o coração e a mente abertos para acolher o diverso, em suma, uma organização saudável e produtiva.

Diversas corporações adotam políticas de qualidade de vida, tomando como base alguns conceitos que trazem retornos substanciais, entre eles:

a) Atendimento às demandas do negócio, ao mesmo tempo que ocorre o equilíbrio entre objetivos e interesses pessoais.

b) É o cliente quem fazo negócio, não só o cliente externo, mas também o interno (ocolaborador).

c) Satisfação: as pessoas veem nas tarefas suas próprias realizações como seres humanos; e na organização, a possibilidade de fazer e ter um futuro melhor.

d) Os interesses da organização e das pessoas são inseparáveis.

e) Foco em resultados e não em estatística de horas trabalhadas.

Sem dúvida, a Adoção da Administração por Exceção, proporcionando flexibilidade no horário, traz vantagens aos empregados e à organização. Com a implantação dessa política, os empregados podem gerir melhor seus compromissos pessoais e profissionais, resultando em mais motivação e orgulho pelo que fazem e em relação à organização em que trabalham. O orgulho 
surge quando uma sensação de sucesso é sentida e, por sua vez, essa sensação é concreta quando se dá o devido e merecido reconhecimento pelo que é feito.

Em suma, os ganhos reais da Administração por Exceção:

- Humanização do trabalho.

- Modernização dos métodos de trabalho.

- Maior integração chefe-empregados.

- Responsabilidades compartilhadas.

- Melhoria da imagem da empresa.

- Economia de recursos humanos e financeiros.

- Evidência de que há constante busca de ganhos em qualidade.

- Transparência na relação empresa-empregado.

- Estímulo ao exercício do talento de cada um, com o reconhecimento do senso de responsabilidade do profissional.

- Obtenção de melhores resultados.

- Impacto positivo, com aumento da produtividade e da motivação.

- Concordância com os preceitos preconizados pela Qualidade e pelos canais de cidadania.

\section{CONSIDERAÇÕES FINAIS E UMA PROPOSTA}

No decorrer das últimas décadas, as organizações vêm se definindo no cenário mundial: cada vez mais estão assumindo a participação dos empregados nos resultados, interessadas que estão em motivá-los e integrá-los para a boa gestão.

Equipes integradas aos processos produtivos e motivadas caminham na busca dos objetivos para elas definidos, constituindo assim requisitos fundamentais de sobrevivência das organizações para alcançar os resultados essenciais para a perenização de seus negócios.

As organizações têm de estar preparadas para as tendências futuras das necessidades de seus empregados. O investimento em aspectos físicos, tecnológicos e em recursos humanos traz como efeito tanto o aumento da produtividade quanto o de credibilidade - nacional e internacional.

Há de se traçar, então, programas de adequação às novas realidades, com uma forte atuação da gestão estratégica de pessoas e avançando em pontos relevantes no ambiente organizacional. Assim, surge a Administração por Exceção, uma ousadia.

Com a Implantação da Administração por Exceção, a Bayer (em 1992) ganhou em produtividade e chamou a atenção, na época, de empresas como (só para citar) a Telecomunicações do Estado do Rio de Janeiro (Telerj, absorvida pela Telemar e atual Oi), IBM, Souza Cruz, Alcoa Alumínios, Acesita (atual Aperam South America, em Timóteo/MG), Albras - Alumínio Brasileiro S.A. (Belém/PA), ATH - Albarus Transmissões Homocinéticas Ltda. (Rio Grande do Sul) e o Grupo LPC (dono das marcas Danone, Terra Branca e Poços de Caldas), que também aboliram o cartão de ponto.

Cada vez mais, as empresas deixam de relacionar produtividade, criatividade e eficiência à 
carga horária. As empresas estão mudando o senso do tempo, ou seja, estão substituindo o controle dos empregados por motivação e responsabilidade.

\subsection{Proposta - Administração por Exceção}

Como já está no contrato de trabalho, como fica o horário do empregado no sistema Administração por Exceção:

a) Fica mantido o horário-padrão da jornada.

b) Registram-se apenas as exceções: faltas, saídas antecipadas, ausências temporárias e horas extras.

c) Caso o empregado não registre essas ocorrências, o chefe imediato tem como fazê-lo.

d) O próprio empregado terá a liberdade para consultar o banco de dados e verificar suas horas extras, faltas e/ou atrasos.

e) No cartão serão anotadas as simbologias existentes, bem como auxílios e gratificações.

f) O reconhecimento pela empresa do cumprimento do horário será assinalado no cartão de ponto.

Ao final do mês, o registro de frequência (espelho de ponto) do empregado é validado, por exemplo, usando uma das duas formas abaixo:

1ª FORMA: assinalar somente as exceções, os demais dias virão em branco e o espelho de ponto conterá o seguinte texto: "Nos dias não assinalados a empresa e o empregado deste espelho reconhecem o cumprimento da jornada de trabalho, de acordo com o horário definido no contrato de trabalho". E tanto o empregado quanto o chefe assinam o espelho de ponto.

$2^{\text {a }}$ FORMA: assinalar as exceções e, para os dias normais, em vez de deixar em branco, são registrados os horários-padrão de entrada e saída. E tanto o empregado quanto o chefe assinam o espelho de ponto.

Nas duas formas de espelho de ponto descritas acima, a empresa tem a prova que se faz necessária para o atendimento do artigo 74 da Consolidação das Leis do Trabalho (CLT).

No sistema Administração por Exceção, ficam mantidos:

a) Permanência diária superior à jornada de trabalho gera crédito. Inferior à jornada de trabaIho gera débito.

b) O intervalo mínimo para almoço.

c) Os abonos estabelecidos em acordo coletivo.

d) Os códigos de ocorrência de frequência.

e) A flexibilidade permitida pela empresa. 


\section{REFERÊNCIAS}

BEZERRA, Élida. P\&G: funcionários de bem com o relógio. Disponível em: http://www.rh.com.br/portal/imprima.php?cod=6042.

BOTELHO, Eduardo Ferreira. Do gerente ao líder: a evolução do profissional. 2. ed. São Paulo: Atlas, 1991.169 p.

CONSOLIDAÇÃO DAS LEIS DO TRABALHO (CLT). Disponível em: http://www.planalto.gov.br/ccivil_03/decreto-lei/Del5452.htm.

CROSBY, Philip B. Qualidade - falando sério. Tradução de José Carlos Barbosa dos Santos. Revisão técnica Carlos de Mathias Martins. São Paulo: McGraw-Hill, 1990. 200 p.

DRUCKER, Peter. Inovação e espírito empreendedor: prática e princípios. São Paulo: Ed. Pioneira, 1998.

FERREIRA, Mário César. O Mito do Relógio de Ponto. Correio Braziliense, Brasília, DF, cad. 1, p. 13, 29 jan. 2007.

FONTES, Lauro B; GOTTSHALK Edson; BORBA, Gelmirez G. Produtividade. Prêmio Fundação Emílio Odebrecht, 1982.

GIANGRANDE, Vera; FIGUEIREDO, José Carlos. O cliente tem mais do que razão: a importância do Ombudsman para a eficácia empresarial. São Paulo: Gente, 1997. 120 p.

GRISCI, C. L. I. Trabalho, tempo e subjetividade: a reestruturação do trabalho bancário. 2000. Tese de Doutorado pela Pontifícia Universidade Católica do Rio Grande do Sul, Porto Alegre, 2000.

ISTO É. Medicina \& Bem-Estar. Revista n 1566, 6 out. 1999, p. 55.

Negócios: Tempos modernos. Revista n 1211, 16 dez.1992, p. 50 e 51.

O'REILLY III, Charles; PFEFFER, Jeffrey. Talentos Ocultos: como as melhores empresas obtêm resultados extraordinários com pessoas comuns. Rio de Janeiro: Ed. Campus, 2001.

SEMLER, Ricardo. Virando a própria mesa. São Paulo: Best Seller, 1988. 274 p.

TELERJ. Tendências de mudança cultural nas relações Empresa x Empregados. Rio de Janeiro: RHA, mar. 1995.

VALLE, Maria Auxiliadora de Medeiros. Relatório Ouvidoria Interna do Serpro. Brasília: OUVDID/GABDP. 2004. 24 p.

et al. [Programa de Qualidade no Desenvolvimento]. In: PROGRAMA DE QUALIDADE NO DESENVOLVI$\overline{M E N T O}, 1995$, Rio de Janeiro, RJ. Sondagem realizada nos Polos/RJ e relatórios finais das turmas do curso "Flexibilidade para mudanças na Qualidade", realizado no Serpro, Rio de Janeiro, RJ, entre dez.1994 e jun. 1995.

VILANOVA, Fátima. Participação e cidadania. Fortaleza: Imprece, 2012. 117 p. 